\title{
Transport properties of solid state crown ether channel systems
}

\author{
Katharina M. Fromm ${ }^{a, *}$, Rémi D. Bergougnant ${ }^{b}$ \\ ${ }^{a}$ University of Fribourg, Department of Chemistry, Chemin du Musée 9, CH-1700 Fribourg, Switzerland \\ ${ }^{\mathrm{b}}$ University of Basel, Department of Chemistry, Spitalstrasse 51, CH-4056 Basel, Switzerland
}

\begin{abstract}
Single crystals of $\left[\left(\mathrm{H}_{2} \mathrm{O}\right) \subset(\mathrm{DB} 18 \mathrm{C} 6)\left(\mu_{2}-\mathrm{H}_{2} \mathrm{O}\right)_{2 / 2}\right]\left[\left(\mathrm{H}_{3} \mathrm{O}\right) \subset(\mathrm{DB} 18 \mathrm{C} 6)\left(\mu_{2}-\mathrm{H}_{2} \mathrm{O}\right)_{2 / 2}\right] \mathrm{I}_{3} \mathbf{1}$ were shown to possess ideally stacked crown ether molecules which form channels running in one direction through the solid state structure. By immersion of single crystals of 1 into $\mathrm{NaOH}$, ion exchange takes place to yield the compound $\left[(\mathrm{Na}) \subset(\mathrm{DB} 18 \mathrm{C} 6)\left(\mu_{2}-\mathrm{H}_{2} \mathrm{O}\right)_{2 / 2}\right]\left[(\mathrm{Na}) \subset(\mathrm{DB} 18 \mathrm{C} 6)\left(\mu_{2}-\mathrm{OH}\right)_{2 / 2}\right] \mathrm{I}_{3} 2$, with slightly but significantly different cell parameters. Both compounds were tested for transport properties through these channels by using two different devices, one for water transport, the other for $\mathrm{NaOH}$ transport, through single crystals of $\mathbf{1}$ and $\mathbf{2}$, respectively. The results indicate that transport can take place via a hopping mechanism.
\end{abstract}

Keywords: Ion channels; Transport properties; Water channels; Dibenzo-18-crown-6

\section{Introduction}

Water molecules and ions play important roles in the biological cells. To transport these species through cellular membranes, life has produced a wide diversity of water molecules and ion channels $[1,2]$. While large-pore channels permit the passage of ions more or less indiscriminately, the archetypal channel pore is just one or two atoms wide at its narrowest point. It conducts a specific ion, such as sodium or potassium, and conveys it through the membrane single file, nearly as quickly as the ions move through a free fluid. Among the most studied channels are (i) the potassium ion channel and (ii) aquaporins. Aquaporins are a class of integral membrane proteins that form pores in the membrane of biological cells and selectively conduct water molecules in and out through an unidirectional process, while preventing the passage of ions and other solutes, thanks to simple electrostatic interactions. Water molecules traverse the narrowest portion of the

\footnotetext{
* Corresponding author.

E-mail address: katharina.fromm@unifr.ch (K.M. Fromm).
}

channel single file. The presence of water channels increases the permittivity of membranes to water by as much as 10 fold. However, because the process is passive, aquaporins cannot reverse the direction of the osmotic gradient driving the flow of water [3]. In cell biology, potassium channels are among the most common type of ion channels together with sodium or ATPase channels. They form potassium-selective pores that span cell membranes [4]. These examples of channel systems furnish also good models of ion carriers which could be used in nanotechnology. Therefore great efforts have been made in chemical research to design mimicking ion channels. Among the compounds used by chemists and biologists, two families have taken an important place in the literature: crown ethers and calix $[n]$ arenes, though porphyrins should be mentioned as well [5-31]. We focus here on the use of crown ethers as scaffold molecules to build channels. Some channel systems have already been realized earlier, for instance the most known "chundles" reported by Jullien and Lehn [32], the bola-amphiphiles of Fyles et al. [33], Nolte's polymerized isonitriles [34], Voyer's crown substituted peptides [13], the redox-switchable systems of Hall et al. [35], and the steroid-substituted crowns of Pechulis et al. [36]. 


\section{Results and discussion}

Dibenzo-18-crown-6 (DB18C6) is a cyclic polyether ligand with two phenyl groups at opposite positions to each other. The structure is not planar and the mean planes of the phenyl groups form an angle of circa $150^{\circ}$. This has been confirmed by theoretical calculations to be a stable conformation of this ligand [37]. Potentially, DB18C6 should be able to stack on top of each other to yield a one-dimensional (1D) chain structure due to packing via $\pi-\pi$ interactions. Upon stacking, the aromatic rings could be packed in such a way as to obtain interactions of $\mathrm{H}$ atoms of one with the ring current of the next neighbor molecule. Indeed, with the aim of obtaining a 1Dstructure with a metal ion, the compound [ $\left(\mathrm{H}_{2} \mathrm{O}\right)(\mathrm{DB} 18 \mathrm{C} 6)$ $\left.\left(\mu_{2}-\mathrm{H}_{2} \mathrm{O}\right)_{2 / 2}\right]\left[\left(\mathrm{H}_{3} \mathrm{O}\right)(\mathrm{DB} 18 \mathrm{C} 6)\left(\mu_{2}-\mathrm{H}_{2} \mathrm{O}\right)_{2 / 2}\right]\left(\mathrm{I}_{3}\right) \mathbf{1}$ was isolated [38]. This compound was previously described by us $[38,39]$. In the present work, it was, however, obtained by a different synthetic method, and since it is the basis of the results described further on, its structure is briefly discussed again here.

Compound 1 crystallises as red-brown needles in the orthorhombic space group Pccn (no. 56) with two independent halfmolecules per asymmetric unit (Fig. 1). The structure of $\mathbf{1}$ is composed of two different channels in a crystallographic point of view: channel 1, stacking almost perfectly around the oxygen atoms $\mathrm{O} 7$ and $\mathrm{O} 8$, and channel 2, featuring an offset stacking around the oxygen atoms O9 and O10. Although it was impossible to attribute protons during the refinement of the structure, the presence of $\mathrm{H}_{3} \mathrm{O}^{+}$is necessary to keep the compound neutral. At first sight, these cations seem to be statistically shared between both channels but only one channel coordinates the hydronium ion. This can be derived from the fact that packing in each channel is different. While channel
1 stacks closer to being eclipsed, channel 2 features a twist angle from one DB18C6 to the next of circa $10^{\circ}$. This difference in stacking can be attributed to a different filling of the channel. We propose that channel 2 carries alternately hydronium ions and water molecules. Hydronium ion $\mathrm{O} 8$ is coordinated by the ligand crown ether and is almost included in the plane defined by the six oxygen atoms of this latter. The coordination sphere is completed by the oxygen atoms $\mathrm{O} 7$ and its symmetry equivalent of the two nearby water molecules. Such an arrangement generates an infinite $\mathrm{H}$-bonded chain with the oxygen atoms of $\mathrm{H}_{3} \mathrm{O}^{+}$and $\mathrm{H}_{2} \mathrm{O}$ on a twofold axis $(1 / 4,3 / 4$, $z(d)$ ). Channel 1 is similar to channel 2 but the hydronium ions are replaced by water molecules. In this case, the infinite column of water molecules $\mathrm{O} 9, \mathrm{O} 10$ is also situated on the twofold axis $(1 / 4,1 / 4, z(c))$. None of the oxygen positions in the centre of the channels, O7, O8, O9, O10, could be refined with alkali metal ions (refinement and structure factor are too bad) instead of oxygen atoms of water molecules, as will be important for the derived compound 2. The two channels are parallel to each other and arranged in an alternating fashion along the $c$-axis. The counter ions, the linear anions $\mathrm{I}_{3}^{-}$, follow the same parallel orientation and fill the voids between the channels.

With our new synthetic approach, large quantities of air-stable single crystals of $\mathrm{cm}$-dimensions in length were obtained (Picture 1). Under the polarisers of a light microscope, they show a strong dichroism (measured by Dr. Jean-Pierre Rivera at the University of Geneva) depending on the angles of the polarisers [40]. The red-brown color is typical for the triiodide absorptions at 288 and $350 \mathrm{~nm}$. [41].

When single crystals of $\mathbf{1}$ are immersed into an aqueous solution of $\mathrm{NaOH}$, ion exchange and substitution of $\mathrm{H}_{2} \mathrm{O}$ by

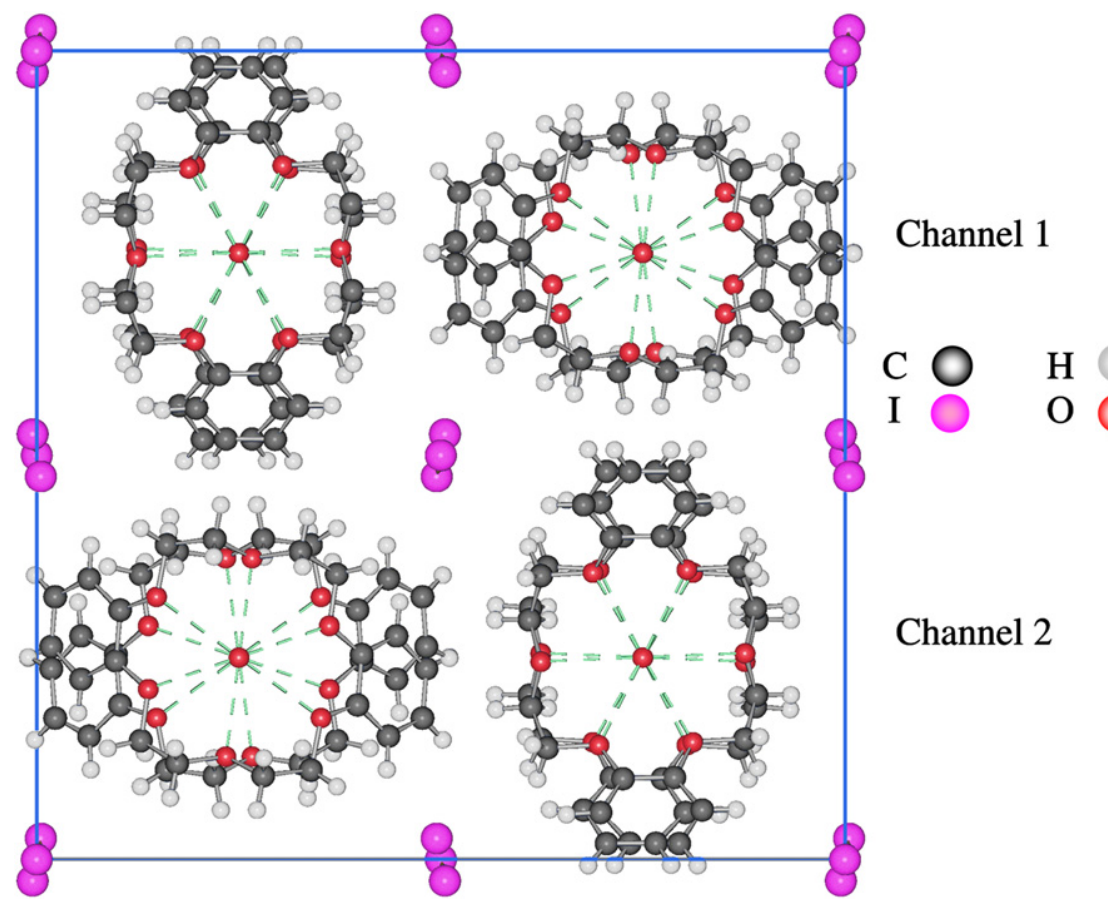

Fig. 1. View on top of the channels formed in $\mathbf{1}$. 


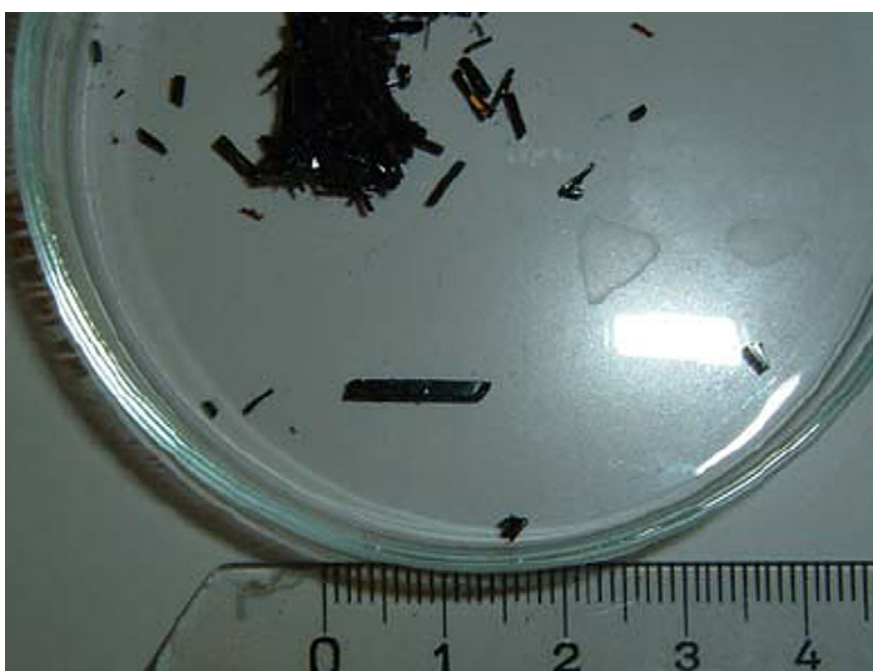

Picture 1. Photo of single crystals of $\mathbf{1}$.

$\mathrm{NaOH}$ is observed without dissolution of the single crystals, thus compound $\mathbf{2}$ is isostructural to $\mathbf{1}$, and compound $\mathbf{2}$ is also obtained as red-brown needles in the orthorhombic space group Pccn (no. 56) with two independent half-molecules in the asymmetric unit. As shown in Fig. 2, the organisation of the cell remains the same as in 1: two types of channels surrounded by parallel triiodide anions. It was not possible to obtain crystals of 2 by classical synthesis due to the reactivity of diodine $\left(\mathrm{I}_{2}\right)$ with sodium hydroxide. In $\mathbf{2}$, the unit cell parameters $a$ and $b$ are smaller by circa $0.1 \AA$ than in $\mathbf{1}$ which is reflected in a smaller unit cell volume by $26 \AA^{3}$. Again two different channels can be identified: channel 2 with an almost perfect stacking of DB18C6 ligands and channel 2 with offset packing of DB18C6 molecules. Channel 1 can be described as a linear chain of alternating hydroxide anions and sodium cations in which the cations are coordinated by DB18C6 in a motif of a distorted hexagonal bipyramid (Fig. 3). Each bipyramid is linked to the next via a hydroxide anion. On the one hand, the distance $\mathrm{Na}^{+}-\mathrm{OH}^{-}$is 1.92(1) $\AA$ and thus is shorter than the distance $\mathrm{O} 8-\mathrm{O} 7$ in $\mathbf{1}$. On the other hand, the distance $\mathrm{Na}^{+}-\mathrm{OH}$ (bridging) is longer than the distance O8-O $7^{\prime}$ in 1 with a length of 2.771(1) $\AA$. The $\pi$-stacking is weaker than in $\mathbf{1}$ with a distance of $3.877 \AA$ on an average between aromatic rings. The presence of $\mathrm{OH}^{-}$is confirmed by IR and a ${ }^{1} \mathrm{H}$ NMR signal at $2.6 \mathrm{ppm}$ which is in agreement with the literature but slightly shifted by $0.4-0.6 \mathrm{ppm}[42,43]$. The broad characteristic IR-band of water in $\mathbf{1}$ is replaced by two signals around $3616 \mathrm{~cm}^{-1}$ in 2 . One can be attributed to $\nu_{\mathrm{OH}}$ stretching deformation of hydroxide anions, and the second attributed to the $\nu_{\mathrm{OH}}$ stretching of independent water molecules. In the other channel of $\mathbf{2}$, there is an alternation of sodium ions and water molecules. Here, the distance $\mathrm{Na}^{+}-\mathrm{O}$ is $2.35(1) \AA$ and longer by circa $0.15 \AA$ than the $\mathrm{O}-\mathrm{O}$ distance in channel 2 of $\mathbf{1}$. This effect results probably from the repulsive dipoledipole interactions between sodium cations and hydrogen atoms of water molecules. The $\mathrm{Na}-\mathrm{O}(\mathrm{DB} 18 \mathrm{C} 6)$ distances are between $2.645(7)$ and 2.800(7) $\AA$. This corresponds well to average values observed in the literature $[43,44]$. The $\mathrm{Na}-\mathrm{O}$ (water) distance of $2.35(1) \AA$ fits also with literature

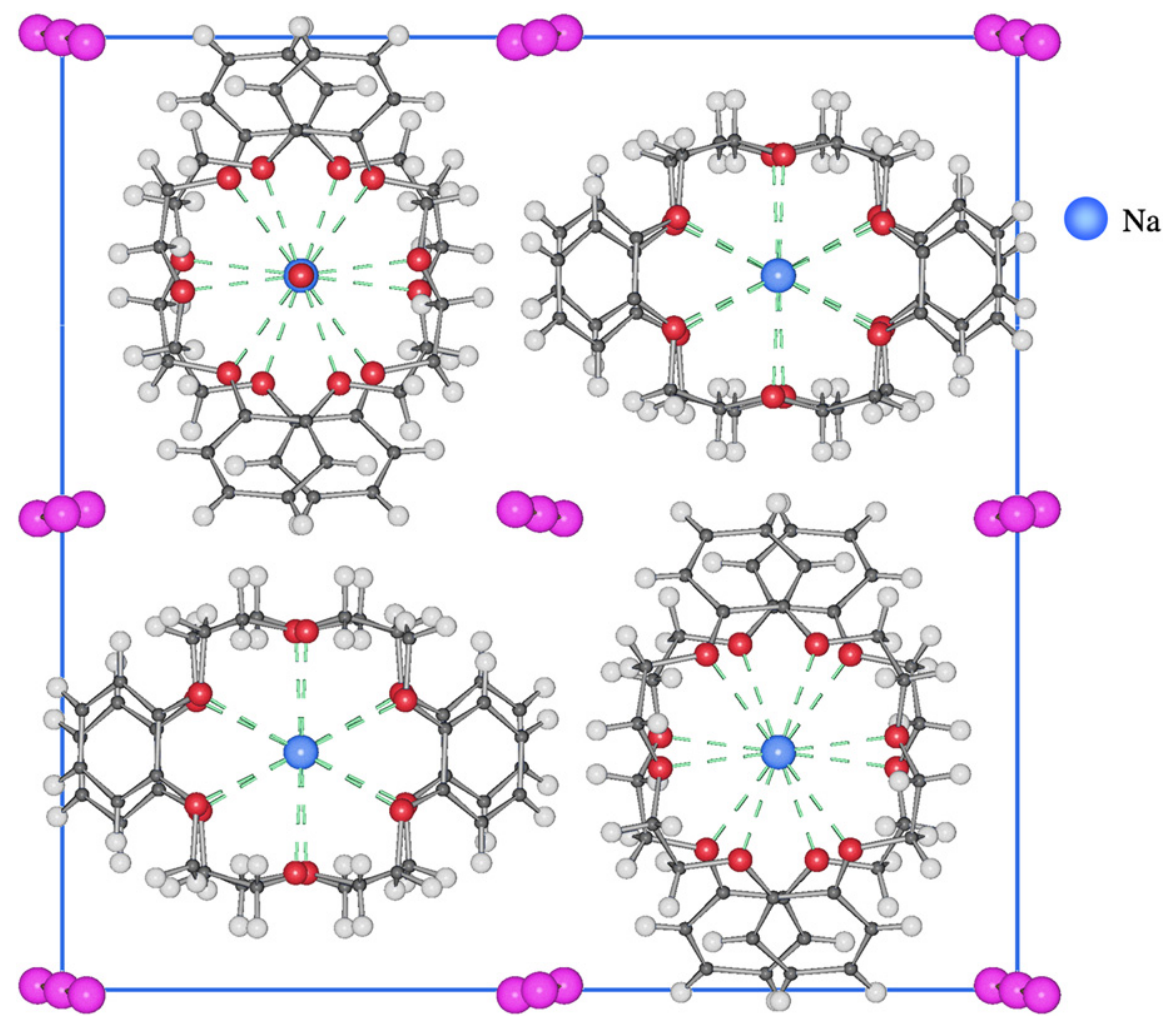

Fig. 2. View on top of the channels found in $\mathbf{2}$. 


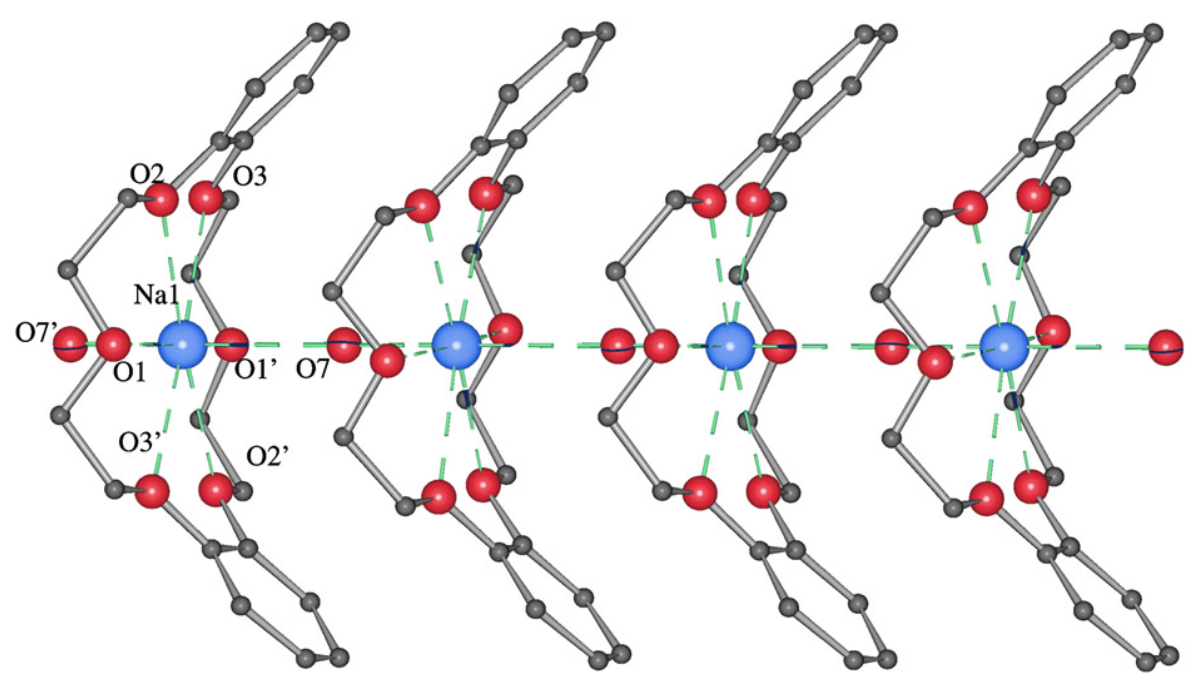

Fig. 3. Side-view of the channel containing $\mathrm{NaOH}$ in 2 .

with the cationic complex of $\left[\mathrm{Na}(\mathrm{DB} 18 \mathrm{C} 6)\left(\mathrm{H}_{2} \mathrm{O}\right)_{2}\right]^{+}$already being reported [45]. In both channels of 2 , the oxygen atoms have elongated ellipsoids along the $c$-axis, and can be also refined on 50:50 symmetric split positions which are on either side of the sodium ions, indicating a certain degree of freedom to move along the $c$-axis of the single crystal.

\subsection{Measurement of water and ion transport}

The transformation of the structure $\mathbf{1}$ into $\mathbf{2}$ indicates that ions can be exchanged in the solid state, and therefore a study of ion exchange was conducted. In the first part, water transport was studied, and in the second part, ion transport was analyzed in more detail. Compound $\mathbf{1}$ forms needle-like single crystals, some of which have a rectangular hole inside, and some of which are smaller and without hole (Picture 2). To avoid the conduction via capillary like in a drinking straw, crystals without hole were used for the following measurements. In order to measure the ion conductivity across single crystals of $\mathbf{1}$ which are not hollow, a small device A was constructed for the fixation of such a single crystal (Scheme 1a). The device A is composed of four parts: one NMR tube (a) (easy to remove to follow the experiment by ${ }^{1} \mathrm{H} \mathrm{NMR}$ ), one reservoir (b) to collect the excess of deuterated solution above the NMR tube composed of a syringe with a needle descending into an NMR tube, one compartment (c) composed of a syringe where a single crystal of $\mathbf{1}$ is in touch with deuterated solution, no grease was in contact with the deuterated solution, one reservoir (d) containing slightly acidic water due to dissolved carbon dioxide and on which the crystal of $\mathbf{1}$ is fixed with non-proton-conducting grease (the grease was tested previously as a blank and was proved to be non-conducting). A single crystal of 1 without a hole bridges the two latter reservoirs, the crystal being oriented along the $c$-axis, this being the direction of the channels. In the upper compartment of the device, a solution of a weak aqueous acid provides the protons and water. In the lower compartment, a solution of $\mathrm{D}_{2} \mathrm{O}$ and acetonitrile collects the protons and/or water exchanged via
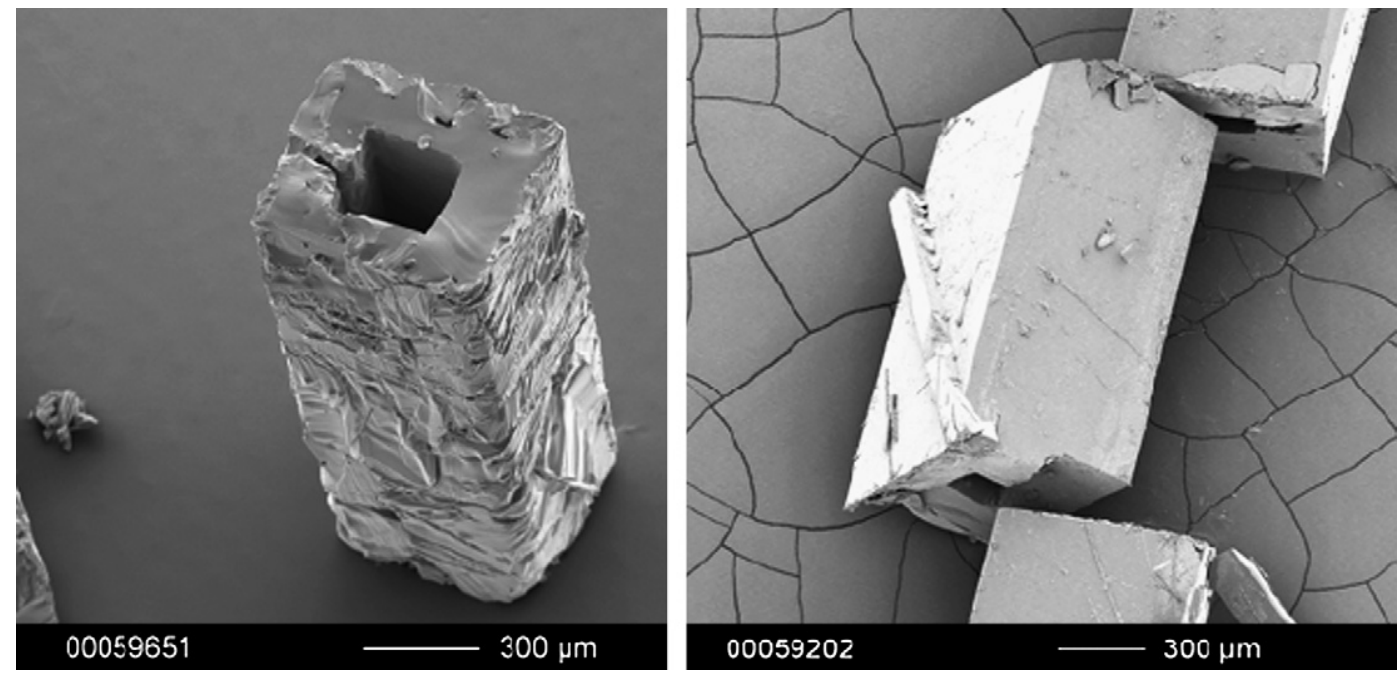

Picture 2. Microscope view of hollow single crystals of $\mathbf{1}$. 
(a)

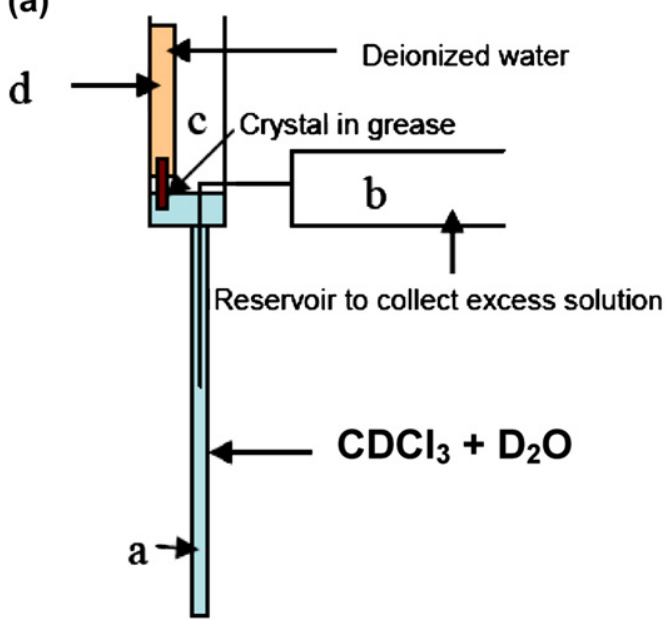

(b)

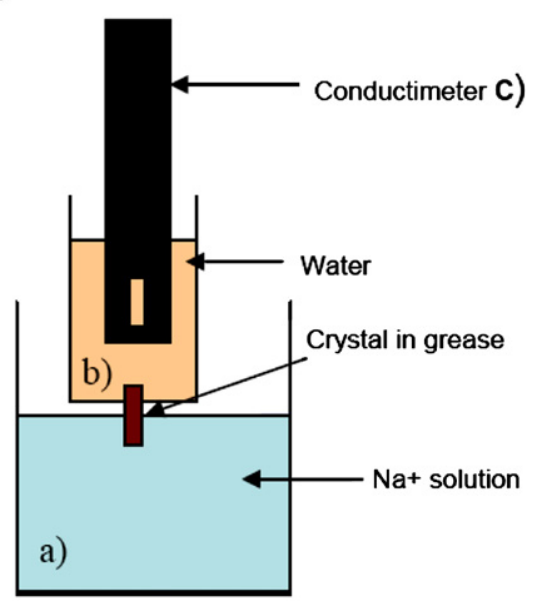

Scheme 1. (a) Device A; (b) Device B.

the single crystal of $\mathbf{1}$. The measurement of proton concentration was followed with a $250 \mathrm{MHz}$ Bruker Advance spectrometer, at $298 \mathrm{~K}$. In order to make sure that the grease is not conducting and that nothing can pass via the interface grease-single crystal, a long, non-hollow crystal of $\mathbf{1}$ was chosen and put in contact with the deuterated solution only with the tip of the crystal. The deuteration of the crystal does not seem to occur during the experiment.

The measurement of proton/water transport is made with a solution of water at $\mathrm{pH}=6$ (acidified by dissolved carbon dioxide). The $\mathrm{D}_{2} \mathrm{O} / \mathrm{CD}_{3} \mathrm{CN}$ solution is in the ratio $(3: 1)$. The measurements were done every $30 \mathrm{~min}$ at room temperature $\left(26^{\circ} \mathrm{C}\right)$. Curve 1 reports the results as derived from the integration of the ${ }^{1} \mathrm{H}$ proton signals at $4.515 \mathrm{ppm}$; the signal for water increases with time (Fig. 4). As we observe no shift of the water signal during the time of the measurement, or appearance of a second signal, the concentration of $\mathrm{H}_{3} \mathrm{O}^{+}$is either very much smaller than one of the $\mathrm{H}_{2} \mathrm{O}$, and it is not possible to differentiate two signals on the ${ }^{1} \mathrm{H}$ NMR spectrum, or there is simply $\mathrm{H}_{2} \mathrm{O}$ transport through single crystals of $\mathbf{1}$. Therefore the number of protons was integrated on the $\mathrm{H}_{2} \mathrm{O}$ signal. As shown in curve 1, the transport is linear and around 9 to $10 \mathrm{H}$ atoms exchange per hour with respect to the signal for $\mathrm{CD}_{2} \mathrm{HCN}$, which stem from the $99 \%$ deuterated acetonitrile molecules. Absolute quantification is, however, not possible here as the quantity of protonated $\mathrm{H}_{2} \mathrm{O}$ in $\mathrm{D}_{2} \mathrm{O}$ is not indicated, but was present to some extent in the initial $\mathrm{D}_{2} \mathrm{O}$ in spite of its indication of $100 \% \mathrm{D}_{2} \mathrm{O}$. The channel 1 is probably the only one to conduct protons in the form of neutral water because if hydronium ions were transported, moving counter ions would also be needed. In the absence of moving counter ions in the crystal structure, the conclusion is that only half of the structure is conducting neutral water molecules. This relatively slow process could be due to a hopping conduction through the channel as proposed in Scheme 2. The slight difference of slope in the beginning may be due to the use of a dried crystal.

For the measurement of ion (i.e. sodium ion) transport through single crystals of $\mathbf{1}$ and $\mathbf{2}$, respectively, device $\mathrm{B}$ was constructed (Scheme 1b). Device B is composed of three parts: one reservoir (a) containing a $1 \mathrm{M}$ in $\mathrm{Na}^{+}$solution $(\mathrm{NaOH})$, one compartment (b) filled with deionised water on which 1 is fixed, and one conductimeter (c) in this latter. Again, a single crystal of $\mathbf{1}$ bridges the two compartments. In the upper one, the dionized water will be enriched with $\mathrm{Na}^{+}$due to osmotic pressure. The measurement of conductivity was recorded by a WTW Tetracon 325 conductimeter and its WTW 720 unit. Upon ion or $\mathrm{NaOH}$ transport of 1, transformation into compound $\mathbf{2}$ should occur. In order to make sure that the grease is not conducting and that nothing can pass via the interface grease-single crystal, a long crystal of $\mathbf{1}$ was chosen and put in contact with the sodium hydroxide solution only with the tip of the crystal.

The measurement of ion conductivity was carried out at room temperature $\left(26^{\circ} \mathrm{C}\right)$. The conductivity was measured every $30 \mathrm{~min}$. Curve 2 shows the results (Fig. 5). Here again, a linear behavior of the conductivity as a function of time is observed. The same singularity noticed at the beginning previously for proton exchange is also present. Besides the fact of crystal hydration, the ionic nature of the guest plays an important role in the shape of the curve 2 . The conductivity augments fast, which is probably due to cation and anion migration, in that case $\mathrm{Na}^{+}$and $\mathrm{OH}^{-}$. After the measurement,

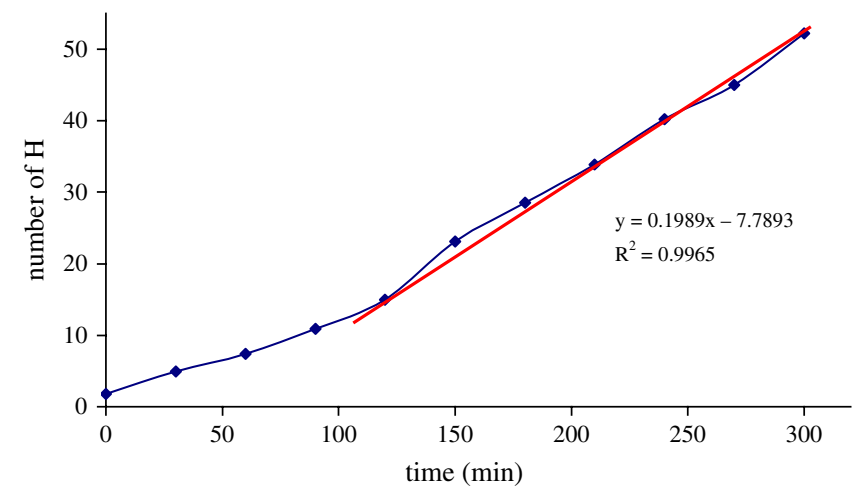

Fig. 4. Curve 1 showing the increase of the ${ }^{1} \mathrm{H}$ NMR signal for water as a function of time. 


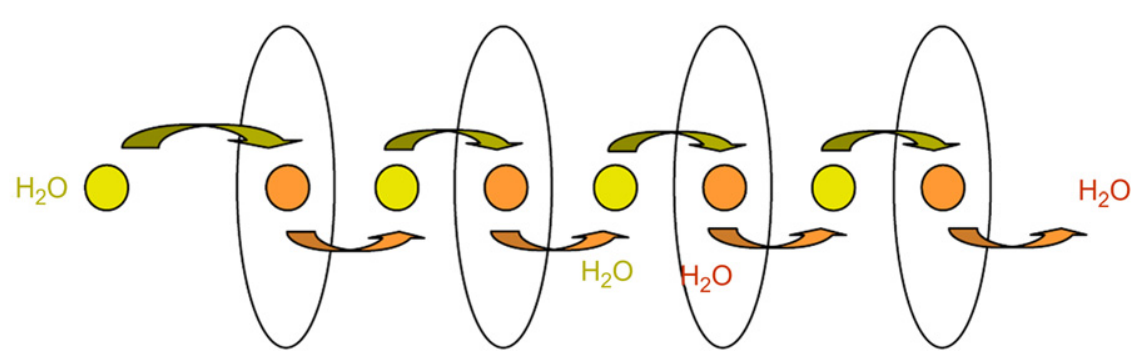

Scheme 2. Proposed hopping mechanism through the 1D-channels maintained by the DB18C6 molecules in 1.

an iodide test with silver nitrate was made. No iodide trace was found in the final solution. $\mathrm{Na}^{+}$ions seem to move faster in the channel because the slope change occurs after $60 \mathrm{~min}$ instead of $120 \mathrm{~min}$ as in the case of $\mathrm{H}_{2} \mathrm{O}$. This can be due to the fact that DB18C6 is fitted to sodium ions with a diameter of $1.90 \AA$ while water molecules are bigger with a diameter of $2.8 \AA$. Another effect can be the hydration energy set free upon migration of $\mathrm{Na}^{+}$from the channel into the water solution. Analysis of the water enriched with sodium ions via this osmotic process, using AAS, reveals a concentration of $6.50 \times 10^{-4} \mathrm{~mol} / \mathrm{L}$. In other words, for an initial volume of $4 \mathrm{~mL}, 2.60 \times 10^{-6} \mathrm{~mol}$ of sodium ions are present in the solution after $6 \mathrm{~h}$. If these moles are reported to the crystal surface, it is $3 \times 10^{-5} \mathrm{~mol} / \mathrm{mm}^{2} / \mathrm{h}$ of sodium ions which are passing through the crystal. If this number is related to the surface of the used monocrystal of $\mathbf{1}$ and the number of conducting channels running through this surface, there are $7.31 \times$ $10^{-17} \mathrm{~mol} / \mathrm{h}$ of sodium ions going through a single channel
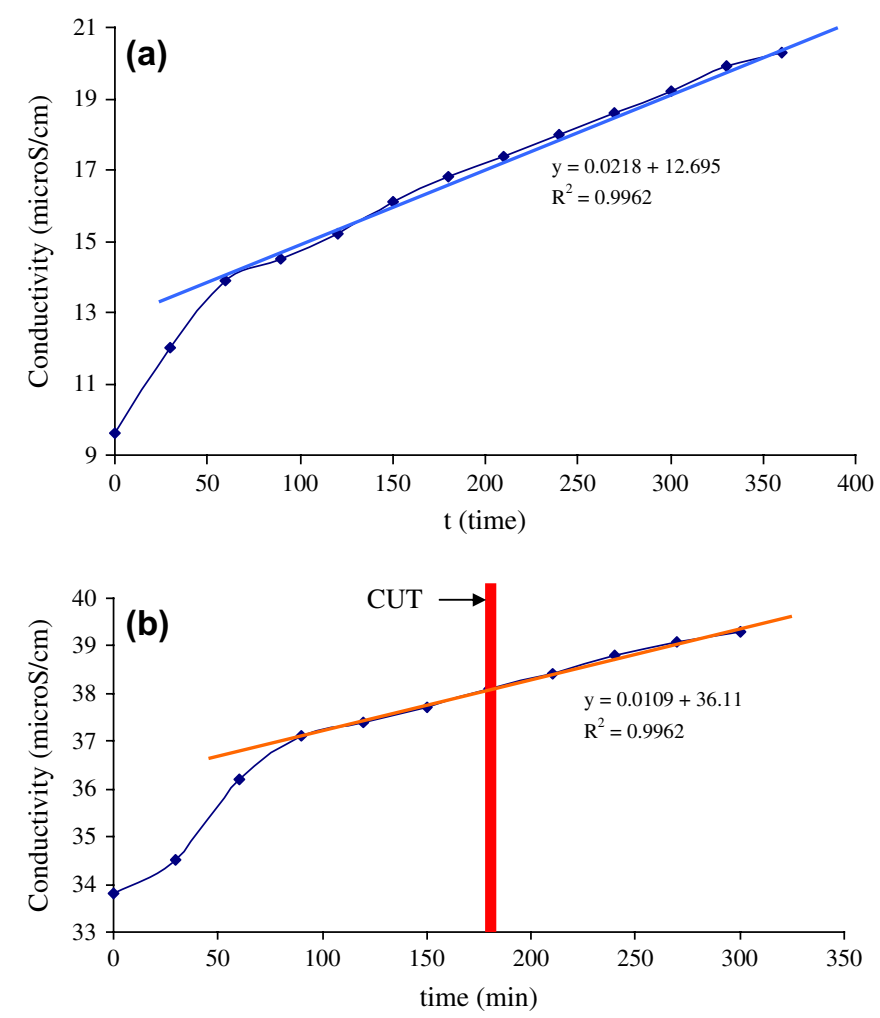

Fig. 5. Curves 2 and 3 showing the increase of conductivity of the solutions obtained after osmotic migration of $\mathrm{NaOH}$ without (a) and with cutting (b) of the used single crystal of $\mathbf{2}$. of 1. This rate lies in the same order of magnitude as transport processes through single crown ether molecules which have been implemented into synthetic cell membranes, and indicates a hopping process as transport mechanism in the solid state [46].

In a third experiment, similar to the second, the crystal was cut to half of its length in order to find out a length dependency of the conduction process. As the slope remains the same, such a length dependency can be excluded. This experiment is in favor of the hopping process theory for $\mathrm{NaOH}$. The data in curve 3 (Fig. 5) also support a hopping process as revealed in Scheme 2.

\section{Conclusions}

Crystals of $\mathbf{1}$ can be transformed into $\mathbf{2}$, and can thus transport ionic species or water molecules through the crown ether tunnels arranged along the $c$-axis of the single crystal. From the speed of transport, one can deduce that the channels show a preference for transporting $\mathrm{Na}^{+}$and $\mathrm{OH}^{-}$ions as compared to water transport. It seems to be a specific transport depending on the ion size. Furthermore, only one channel, i.e. the overall neutral channel containing water molecules or pairs of ions (cations and anions), is conducting. The speed of transport indicates a hopping process through the channels. Such large single crystals could therefore be employed as tiny ion conducting electrodes for small samples.

\section{Experimental}

Synthesis of 1: a procedure different from that given in Ref. [1] is described here to obtain single crystals of $\mathbf{1}$. $0.532 \mathrm{~g}$ ( $1.85 \mathrm{mmol})$ dibenzo-18-crown-6 were dissolved in $20 \mathrm{ml}$ THF and $20 \mathrm{ml} 0.05 \mathrm{M}$ aqueous $\mathrm{I}_{2}$-solution. The beaker was closed with parafilm and the solution was allowed to stand at room temperature for several weeks. After evaporation of solvent, crystals of $\mathbf{1}$ in the form of dark brown needles were isolated, and used for single crystal diffraction. Yield: circa $90 \%$ referring to iodide. ${ }^{1} \mathrm{H} \mathrm{NMR}$ : $\left(\mathrm{CDCl}_{3}, 250 \mathrm{MHz}\right)$ : $\delta(\mathrm{ppm}) 6.94(\mathrm{ArH}), 6.89(\mathrm{ArH}), 4.98\left(\mathrm{H}_{3} \mathrm{O}^{+} \cdot n \mathrm{H}_{2} \mathrm{O}\right), 4.16$ (md, $\mathrm{CH}_{2}$ ), $1.54\left(\mathrm{H}_{2} \mathrm{O}\right)$; IR cm ${ }^{-1}$ : 3649 (s), 2900 (vs), 2724 (m), 2669 (m), 1592 (m), 1455 (s), 1376 (s), 1254 (m), 1217 (m), 1127 (m), 1069 (sh), 951 (sh), 722 (m).

Synthesis of 2: a single crystal of $\mathbf{1}$ was immersed into a $0.1 \mathrm{M} \mathrm{NaOH}$ solution for one day. The crystal was used for diffraction measurements. Yield $100 \%$. ${ }^{1} \mathrm{H} \mathrm{NMR}\left(\mathrm{CDCl}_{3}\right.$, 
$250 \mathrm{MHz}): \delta(\mathrm{ppm}) 6.94(\mathrm{ArH}), 6.89(\mathrm{ArH}), 4.16\left(\mathrm{md}, \mathrm{CH}_{2}\right)$, $2.61\left(\mathrm{~s}, \mathrm{OH}^{-}\right), 1.64\left(\mathrm{H}_{2} \mathrm{O}\right) \mathrm{IR} \mathrm{cm}^{-1}$ : $3616(\mathrm{w}), 2925(\mathrm{w}), 2871$ (w), 1593 (m), 1504 (s), 1448 (s), 1335 (w), 1326 (m), 1247 (s), 1217 (s), 1126 (s), 1060 (s), 1051(s), 941 (s), 910 (m), $854(\mathrm{~m}), 781$ (s), $738(\mathrm{~s}), 599(\mathrm{w})$.

Single crystal data for 2: $\mathrm{C}_{40} \mathrm{H}_{48} \mathrm{I}_{3} \mathrm{Na}_{2} \mathrm{O}_{14}, \quad M=$ $1179.46 \mathrm{~g} \mathrm{~mol}^{-1}$, orthorhombic, space group Pccn (no. 56), $a=21.988(4), b=21.988(4), c=9.393(2) \AA, V=4541.2(2) \AA^{3}$, $Z=4, \quad T=203 \mathrm{~K}, \quad D_{\text {calcd. }}=1.725 \mathrm{Mg} \mathrm{m}^{-3}, \quad \mu \quad($ Mo $\mathrm{K} \alpha)=$ $2.146 \mathrm{~mm}^{-1}, F(000)=2324,22,110$ reflections collected of which 3415 unique and observed, 270 parameters refined, $R$ (int) $=0.0775, \quad R 1=\sum\left|F_{\mathrm{o}}-F_{\mathrm{c}}\right| / \sum F_{\mathrm{o}}=0.0800, \quad w R 2=$ 0.2208 for $I>2 \sigma$ and $R 1=0.816, w R 2=0.2218$ for all data, $\mathrm{GooF}=1.117$.

Crystals of 2 were measured on an STOE IPDS with graphite monochromated Mo K $\alpha$ radiation and an Oxford Cryosystems open flow cryostat [47] on a crystal of $0.10 \times 0.08 \times$ $0.06 \mathrm{~mm}$, and with an absorption correction by analytical integration [48]. The structure was solved with direct methods and refined by full matrix least squares on $F^{2}$ with the SHELX-97 package [49]. All non-hydrogen atoms were refined with anisotropic displacement parameters. The hydrogen atoms were placed in geometrically calculated positions and refined using a riding model. Not all hydrogen atoms for $\mathrm{H}_{2} \mathrm{O}$ and $\mathrm{OH}^{-}$could be found in the Fourier map and were thus not modelled, their positions being ambiguous. The corresponding oxygen atoms could be refined also on split positions on either side of the sodium ions. Crystallographic data for structure 2 have been deposited with the Cambridge Crystallographic Data Centre as supplementary publication no. CCDC643299. These data can be obtained free of charge via www.ccdc.cam.ac.uk/conts/retrieving.html (or from the Cambridge Crystallographic Data Centre, 12 Union Road, Cambridge CB2 1EZ, UK; fax: (+44)1223 336 033; or deposit@ccdc.cam.ac.uk).

\section{References}

[1] D. Purves, G.J. Augustine, D. Fitzpatrick, L.C. Katz, A.S. La Mantia J.O. McNamara, S.M. Williams, Neuroscience, second ed., Sinauer Associates, Sunderland, MA, 2001.

[2] G.J. Siegel, B.W. Agranoff, R.W. Albers, S.K. Fisher, M.D. Uhler, Basic Neurochemistry: Molecular, Cellular, and Medical Aspects, sixth ed., Lipincott-Raven, Philadelphia, 1999.

[3] P. Agre, Proc. Am. Thorac. Soc. 3 (2006) 5-13.

[4] R. McKinnon, Angew. Chem. Int. Ed. 43 (2004) 4265-4277.

[5] M.P. Byrn, C.J. Curtis, I. Goldberg, Y. Hsiou, S.I. Khan, P.A. Sawin, S.K. Tendick, C.E. Strouse, J. Am. Chem. Soc. 113 (1991) 6549-6557.

[6] K.S. Akerfeldt, R.M. Kim, D. Camac, J.T. Groves, J.D. Lear, W.F. DeGrado, J. Am. Chem. Soc. 114 (1992) 9656-9657.

[7] P. Bhyrappa, S.R. Wilson, K.S. Suslick, J. Am.Chem. Soc. 119 (1997) 8492-8502.

[8] T. Schareina, R. Kempe, Z. Anorg. Allg. Chem. 626 (2000) 1279-1281.
[9] S.P. Visser, S. Shaik, J. Am. Chem. Soc. 125 (1992) 7413-7424.

[10] R. Harada, T. Kojima, J. Chem. Soc., Chem. Commun. (2005) 716-718.

[11] H.J. Kim, H.J. Jo, J. Kim, S.Y. Kim, D. Kim, K. Kim, CrystEngComm. 7 (68) (2005) 417-420.

[12] B. Roux, M. Karplus, J. Am. Chem. Soc. 115 (1993) 3250-3262.

[13] N. Voyer, M. Robataille, J. Am. Chem. Soc. 117 (1995) 6599-6600.

[14] D.E. Sagnella, G.A. Voth, Biophys. J. 70 (1996) 2043-2051.

[15] O. Murillo, I. Suzuki, E. Abel, C.L. Murray, E.S. Meadows, T. Jin, G.W. Gokel, J. Am. Chem. Soc. 119 (1997) 5540-5549.

[16] S. Rashid, S.S. Turner, P. Day, M.E. Light, M.B. Hursthouse, S. Firth, J.H. Clark, J. Chem. Soc., Chem. Commun. (2001) 1462-1463.

[17] V. Vijayvergiya, D. Bose, P. Ghosh, S. Ghosh, Eur. Biophys. J. Biophys. Lett. 32 (2003) 724-728.

[18] Y. Li, N. Hao, E. Wang, M. Yuan, C. Hu, N. Hu, H. Jia, Inorg. Chem. 42 (8) (2003) 2729-2735.

[19] S.E. Matthews, P. Schmitt, V. Felix, M.G.B. Drew, P.D. Beer, J. Am. Chem. Soc. 124 (2002) 1341-1353.

[20] J.K. Lee, S.K. Kim, R.A. Bartsch, J. Vicens, S. Miyano, J.S. Kim, J. Org Chem. 68 (2003) 6720-6725.

[21] S. Le Gac, X. Zeng, O. Reinaud, I. Jabin, J. Org. Chem. 70 (2005) 12041210 .

[22] P.D. Beer, M.G.B. Drew, P.A. Gale, M.I. Ogden, H.R. Powell, CrystEngComm. 2 (2000) 164-168.

[23] A.W. Coleman, E. Da Silva, F. Nouar, M. Nierlich, A. Navaza, J. Chem Soc., Chem. Commun. (2003) 826-827.

[24] C. Tedesco, I. Immediata, L. Gregoli, L. Vitagliano, A. Immirzi, P. Neri, CrystEngComm. 73 (2005) 449-453.

[25] B.H. Hong, J.Y. Lee, C.W. Lee, J.C. Kim, S.C. Bae, K.S. Kim, J. Am Chem. Soc. 123 (2001) 10748-10749.

[26] G.W. Orr, L.J. Barbour, J.L. Atwood, Science 285 (1999) 1049-1052.

[27] J.L. Atwood, L.J. Barbour, M.J. Hardie, C.L. Raston, Coord. Chem. Rev. 222 (2001) 3-32.

[28] P.K. Thallapally, G.O. Lloyd, J.L. Atwood, L.J. Barbour, Angew. Chem. 117 (2005) 3916; Angew. Chem. Int. Ed. 44 (2005) 3848-3851.

[29] L.E. Cheruzel, M.S. Pometun, M.R. Cecil, M.S. Mashuta, R.J. Wittebort, R.M. Buchanan, Angew. Chem. Int. Ed. 42 (2003) 5451.

[30] Z. Fei, D. Zhao, T.J. Geldbach, R. Scopellitti, P.J. Dyson, S. Antonijevic, G. Bodenhausen, Angew. Chem. Int. Ed. 44 (2005) 5720-5725.

[31] M. Barbiou, G. Vaughan, A. van der Lee, Org. Lett. 5 (17) (2003) 30733076.

[32] L. Jullien, J.M. Lehn, Tetrahedron Lett. (1988) 3803-3806.

[33] (a) T.M. Fyles, T.D. James, A. Pryhitka, M. Zojaji, J. Org. Chem. 58 (1993) 7456-7468;

(b) L.M. Cameron, T.M. Fyles, C. Hu, J. Org. Chem. 67 (2002) 1548-1553.

[34] M.F.M. Roks, R.J.M. Nolte, Macromolecules 25 (1992) 5398-5407.

[35] (a) C.D. Hall, G.J. Kirkovits, A.C. Hall, J. Chem. Soc., Chem. Commun. (1999) 1897-1899;

(b) A.C. Hall, C. Suarez, A. Hom-Choudhury, A.N.A. Manu, C.D. Hall, G.J. Kirkovits, I. Ghiriviga, Org. Biomol. Chem. 1 (2003) 2973-2982.

[36] A.D. Pechulis, R.J. Thompson, J.P. Fojtik, H.M. Schwartz, C.A. Lisek, L.L. Frye, Bioorg. Med. Chem. Lett. 5 (1997) 1893-1898.

[37] M. Dułak, R. Bergougnant, K. M Fromm, H.R. Hagemann, A.Y. Robin, T.A. Wesołowski, Spectrochim. Acta A 64A (2) (2006) 532-548.

[38] K.M. Fromm, E.D. Gueneau, H. Goesmann, C.G. Bochet, Z. Anorg. Allg. Chem. 629 (4) (2003) 597-600.

[39] E.D. Gueneau, Synthèse et caractérisation de clusters de métaux alcalin et/ou alcalino-terreux, Thèse no. 3452, Université de Genève.

[40] K.M. Fromm, E.D. Gueneau, A.Y. Robin, W. Maudez, J. Sague, R. Bergougnant, Z. Anorg. Allg. Chem. 631 (10) (2005) 1725-1740.

[41] Y.J. Wei, C.G. Liu, L.P. Mo, Guangpuxue Yu Guangpu Fenxi 25 (1) (2005) 86-88.

[42] J. Geier, H. Grützmacher, J. Chem. Soc., Chem. Commun (2003) 29422943.

[43] K.M. Fromm, E.D. Gueneau, J.P. Rivera, G. Bernardinelli, H. Goesmann, Z. Anorg. Allg. Chem. 628 (2002) 171-178.

[44] D.J. Darensbourg, C.G. Bacu, A.L. Rheingold, Inorg. Chem. 26 (1987) 977-980. 
[45] M.R. Truter, M.A. Bush, J. Chem. Soc., Chem. Commun. 21 (1970) $1439-1440$

[46] M.G. Zolotukhin, G. Hernández, M. del Carmen, A.M. Lopez, L. Fomine, G. Cedillo, A. Nogales, T. Ezquerra, D. Rueda, H.M. Colquhoun, K.M. Fromm, A. Ruiz-Treviño, M. Ree, Macromolecules 39 (2006) 4696-4703;

Y. Takeda, Y. Mochizuki, Y. Matsuzaki, S. Katsuta, J. Inclusion Phenom. Macrocycl. Chem. 37 (1-4) (2000) 179-195;
M. Seno, K. Iwamoto, Q.Z. Chen, Electrochim. Acta 35 (1) (1990) 127-134; R.M. Izatt, G.C. Lindh, P. Huszthy, G.A. Clark, R.L. Bruening, J.S. Bradshaw, J.J. Christensen, J. Inclusion Phenom. Mol. Recognit. Chem. 7 (5) (1989) 501-509.

[47] J. Cosier, A.M. Glazer, J. Appl. Crystallogr. 19 (1986) 105.

[48] E. Blanc, D. Schwarzenbach, H.D. Flack, J. Appl. Crystallogr. 24 (1991) 1035.

[49] G.M. Sheldrick, SHELX-97, University of Göttingen, Göttingen, 1997. 